\title{
Anti-Inflammatory Potential of Rape Flower in Lipopolysaccharide-Stimulated RAW 264.7 Macrophages
}

\author{
EUN A HYUN ${ }^{1}$, JONG-SEOK KANG ${ }^{1}$, KYONG-WOL YANG², SEUNG-YOUNG KIM³, \\ SANG-CHEOL KIM ${ }^{4}$, WOOK JAE LEE ${ }^{4}$, NAM HO LEE ${ }^{1}$ and CHANG-GU HYUN ${ }^{1 *}$ \\ ${ }^{1}$ Cosmetic Sciences Center, Department of Chemistry and Cosmetics, \\ Jeju National University, Jeju 63243, Korea. \\ 2Department of Animal Biotechnology, Faculty of Biotechnology, \\ Jeju National University, Jeju 63243, Korea. \\ ${ }^{3}$ Department of BT-Convergent Pharmaceutical Engineering, \\ Sun Moon University, Chungnam 31460, Korea. \\ ${ }^{4}$ Nakdonggang National Institute of Biological Resources, Chungbuk 742-350, Korea. \\ *Corresponding author E-mail: cghyun @ jejunu.ac.kr
}

http://dx.doi.org/10.13005/ojc/320403

(Received: May 07, 2016; Accepted: August 09, 2016)

\begin{abstract}
The present study was undertaken to investigate the anti-inflammatory potential and mechanism of action of the rape flower extract (RFE) in lipopolysaccharide (LPS)-stimulated RAW 264.7 macrophage cells. RFE inhibited nitric oxide (NO), prostaglandin $E_{2}\left(P E_{2}\right.$. interleukin-1â (IL-1â), and IL-6 production in a concentration-dependent manner. RFE effectively attenuated the expression of inflammation-mediating enzymes, inducible nitric oxide synthase (iNOS) and cyclooxygenase-2 (COX-2), at the protein level in a concentration-dependent manner. Additionally, the attenuation of inflammatory responses in RAW 264.7 cells by RFE was closely associated with the suppression of the phosphorylation of extracellular signal-regulated kinase (ERK), eventually blocking the activation of downstream elements contributing to inflammation. RFE HPLC fingerprint indicated the presence of coumestrol. The coumestrol content in RFE was $2.614 \mathrm{iM}$. To evaluate the safety of RFE and its effects on the human skin, human skin primary irritation tests were performed on the normal skin (upper back) of 32 volunteers to determine if any constituent of RFE presented an irritation or sensitization potential. RFE did not induce any adverse reactions. Taken together, our results suggest that RFE may be considered as an anti-inflammatory candidate for topical application.
\end{abstract}

Keywords: Coumestrol, cyclooxygenase-2 (COX-2), extracellular signal-regulated kinase (ERK), inducible nitric oxide synthase (iNOS), rape flower.

\section{INTRODUCTION}

Plant-derived natural products have been a historically rich source of active ingredients in the treatment and prevention of human skin diseases. Numerous cosmetic ingredients for topical applications have been directly or indirectly derived from plants and many high-value plant-derived 
natural products remain undiscovered or unexplored for their pharmacological activity. However, a variety of plant-derived natural products have been studied and used as topical ingredients to treat human skin diseases in Korea ${ }^{1-3}$.

Especially, vegetable plants garnered the attention of the food and cosmetic industries, along with the introduction of the concept of inner beauty. Extracts from many vegetables exhibit significant biological activities, including anti-inflammatory, anti-nociceptive, and antioxidative activities. Brassica $\mathrm{sp}$ (rape) became popular because it presents antigenotoxic, antioxidant, and anti-cancer activities ${ }^{4-5}$. The origin of rape remains unclear, but it most likely originates from the Eurasian region, since the oldest known references to its cultivation (approximately BC 2000) come from India and China. Two types of rape sp., Brassica napus and Brassica campestris, are cultivated in Korea and are called "YouChae" (English names, canola and rape). It is widely distributed in Jeju Island, Korea as an ornamental plant for travelers. Before the flower blooms in the spring, native people of Jeju Island make kimchi (Korean fermented food) with rape flower stalk and leaves. Additionally, the seed of Brassica sp. is known as Woon-Dae-Ja in Korean traditional medicine. It is classified as a prescription drugextravasated blood and to heal inflammation, boil, menstrual pain, and intestinal infarction. Nevertheless, the pharmacological and biological effects of rape flower extract (RFE) on the production of inflammatory mediators in macrophages remain uncharacterized.

Inflammation is a complex event that involves the activation of the immune system by external stimuli. Disruption of the inflammatory response induces a variety of inflammatory diseases such as atopic dermatitis, psoriasis, and arthritis ${ }^{6}$. Interestingly, inflammatory mediators, including nitric oxide (NO), interleukin-6 (IL-6), IL-1 $\beta$, prostaglandin $E_{2}\left(P G E_{2}\right)$, and mitogen-activated protein kinase (MAPK) pathways are key regulators of immune responses and are therefore potential targets for new therapeutic strategies ${ }^{7-8}$. Many studies investigated the potential inhibitory effects of anti-inflammatory products in an in vitro system, lipopolysaccharide (LPS)-stimulated RAW 264.7 macrophages. Using this system, LPS from gram negative bacteria (ex.

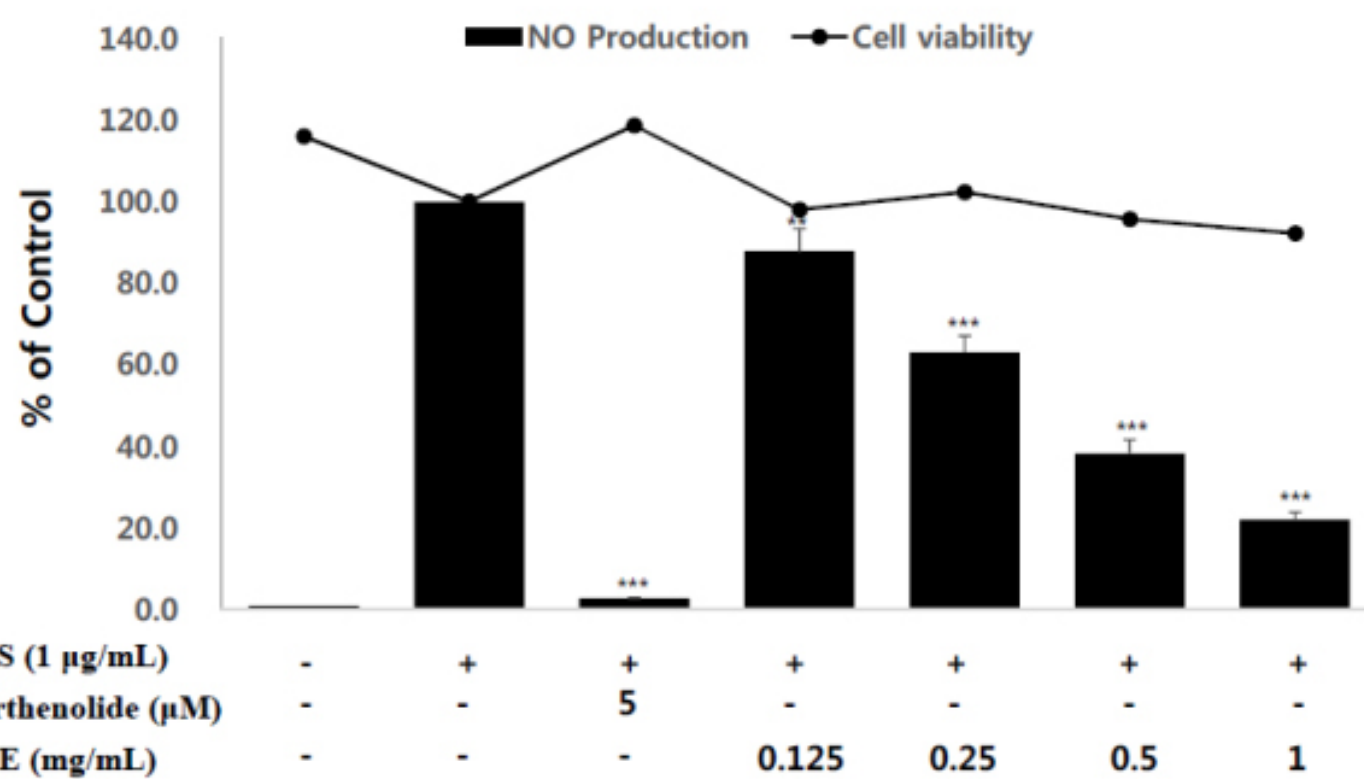

Fig. 1: Effects of RFE on NO production and cell viability of LPS-stimulated RAW264.7 murine macrophages. Cells $\left(1.5 \times 10^{5}\right.$ cells $\left./ \mathrm{mL}\right)$ were pre-incubated for $18 \mathrm{~h}$ and NO production and cell viability were determined in cells stimulated with LPS $(1 \mu \mathrm{g} / \mathrm{mL})$ in the presence or absence of RFE for $24 \mathrm{~h} . \mathrm{n}=\mathbf{3}$ experiments. Values are the mean \pm SEM of triplicate experiments. ${ }^{*}, \mathrm{P}<0.05$;

$$
{ }^{* *}, \mathrm{P}<0.01 \text {; ***, } \mathrm{P}<0.001
$$


E. coli) has become one of the best-characterized stimuli used to induce the up-regulation of proinflammatory mediators such as $\mathrm{NO}$ and $\mathrm{PGE}_{2}^{9-10}$. Therefore, in this study, we used LPS-stimulated RAW264.7 cells to examine the potential antiinflammatory properties of RFE and the underlying molecular mechanisms. RFE suppressed the LPSinduced release of pro-inflammatory factors and the activation of extracellular signal-regulated kinase (ERK), one of the mitogen-activated protein kinases (MAPK). We also performed HPLC fingerprinting and primary skin irritation tests on the human skin for topical application.

\section{MATERIALS AND METHODS}

\section{Material preparation}

Rape flowers were collected in April 2014 on Jeju Island, Korea. A voucher specimen with number CSC-2014-011 has been deposited at the Cosmetic Sciences Center, Department of Chemistry and Cosmetics. For extraction, rape flowers were cleaned, dried at room temperature for 2 weeks, and ground into a fine powder. The dried rape flower powder $(400 \mathrm{~g})$ was extracted with $70 \%$ ethanol $(\mathrm{EtOH} ; 2 \mathrm{~L})$ at $70^{\circ} \mathrm{C}$ for $4 \mathrm{~h}$ and then evaporated under a vacuum. The yield and ratio of this $\mathrm{EtOH}$ extract were $154 \mathrm{~g}$ and $38.0 \%$, respectively.

Table 1: Results of human skin primary irritation test $(n=32)$

\begin{tabular}{|c|c|c|c|c|c|c|c|c|c|c|c|c|c|}
\hline \multirow[t]{2}{*}{ No } & \multirow{2}{*}{$\begin{array}{l}\text { Test } \\
\text { Materials }\end{array}$} & \multirow{2}{*}{$\begin{array}{c}\text { No. of } \\
\text { responder }\end{array}$} & \multirow[b]{2}{*}{$1+$} & \multicolumn{3}{|c|}{$48 h$} & \multicolumn{3}{|c|}{$72 \mathrm{~h}$} & \multicolumn{4}{|c|}{ Reaction grade ${ }^{a}$} \\
\hline & & & & $2+$ & $3+$ & $4+$ & $1+$ & $2+$ & $3+$ & $4+$ & $48 h$ & $72 h$ & Mean \\
\hline 1 & Butylene glycol & 0 & $-b$ & - & - & - & - & - & - & - & 0 & 0 & 0 \\
\hline 2 & RFE (1mg/ml) & 0 & - & - & - & - & - & - & - & - & 0 & 0 & 0 \\
\hline 3 & RFE $(2 \mathrm{mg} / \mathrm{ml})$ & 0 & - & - & - & - & - & - & - & - & 0 & 0 & 0 \\
\hline
\end{tabular}

${ }^{\text {a Reaction grade }}=\Sigma[\{$ Grade $\times$ no. of responders $\} /\{4$ (maximum grade) $\times 32$ (total subjects) $\}] \times 100 \times(1 / 2)$. ${ }^{\mathrm{b}}$ No reaction

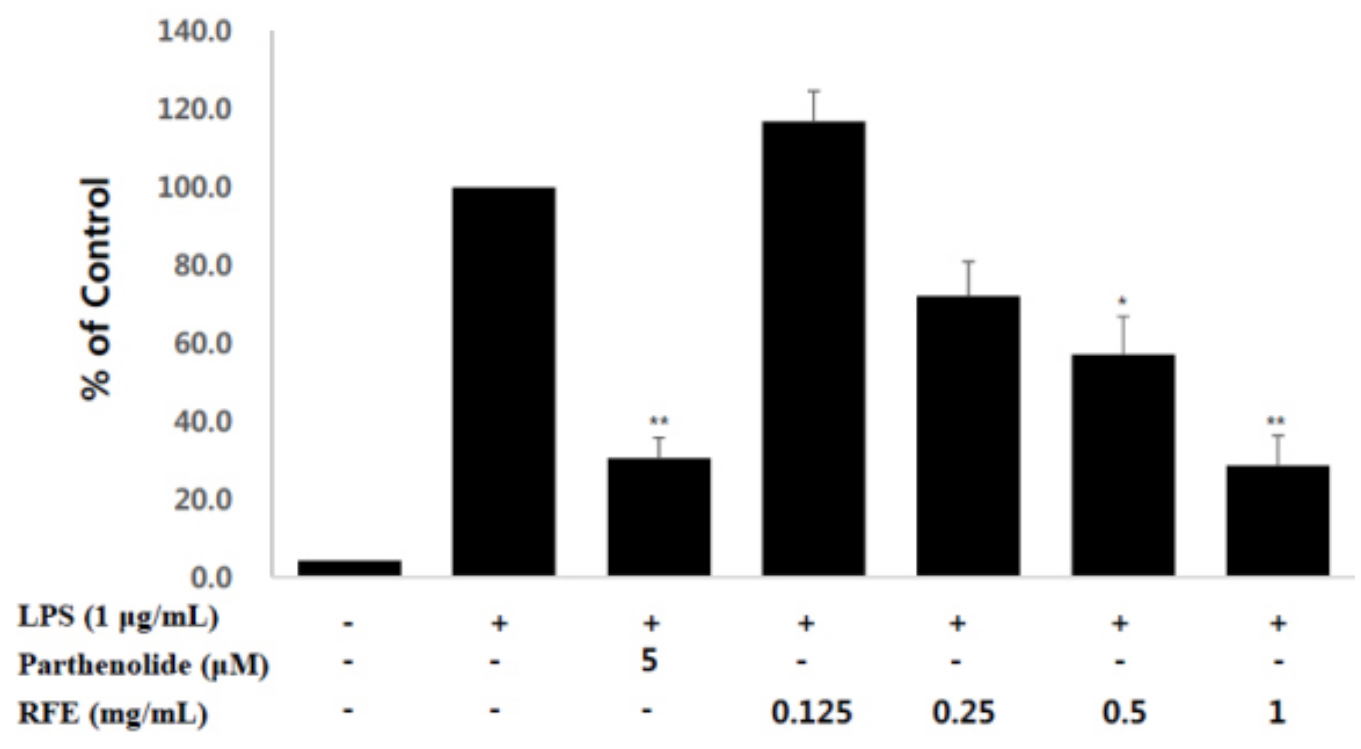

Fig. 2: Effects of RFE on PGE ${ }_{2}$ production in LPS-stimulated RAW264.7 murine macrophages. Cells (1.5 x $10^{5}$ cells $/ \mathrm{mL}$ ) were pre-incubated for $18 \mathrm{~h}$ and $\mathrm{PGE}_{2}$ production was determined

in cells stimulated with LPS $(1 \mu \mathrm{g} / \mathrm{mL})$ in the presence or absence of RFE for $24 \mathrm{~h} . \mathbf{n}=\mathbf{3}$ experiments. Values are the mean \pm SEM of triplicate experiments. ${ }^{*}, \mathrm{P}<0.05 ;{ }^{* *}, \mathrm{P}<0.01$; ${ }^{\star \star *}, \mathrm{P}<$ 


\section{Cell culture}

RAW264.7 cells, a murine macrophagelike cell line (KCLB; Seoul, KOREA), were cultured in Dulbecco's Modified Eagle's Medium (DMEM; GIBCO Inc., NY) supplemented with $10 \%$ fetal bovine serum (FBS; GIBCO Inc.), $100 \mathrm{U} / \mathrm{mL}$ penicillin and $100 \mathrm{mg} / \mathrm{mL}$ streptomycin (GIBCO Inc.). The cells were incubated in an atmosphere of $5 \% \mathrm{CO}_{2}$ at $37^{\circ} \mathrm{C}$ and were subcultured every 3 to 4 days.

\section{Cell viability}

Cell viability was measured by using the conventional 3-(4,5-dimethylthiazol-2-yl)-2,5diphenyltetra-zoliumbromide (MTT) assay, which is based on the reduction of MTT to formazan by mitochondrial dehydrogenase. Briefly, RAW264.7 macrophage cells $\left(1.5 \mathrm{x}\right.$ ? $\left.10^{5}\right)$ were seeded for $18 \mathrm{~h}$, and then treated with LPS and various concentrations of RFE, followed by an additional incubation for 24 $\mathrm{h}$ at $37^{\circ} \mathrm{C}$. The MTT reagent $(0.5 \mathrm{mg} / \mathrm{mL})$ (Sigma, St. Louis, MO, USA) was added to the medium and incubated for an additional $1 \mathrm{~h}$. The medium was then removed and the MTT-formazan was dissolved in dimethylsulfoxide (DMSO). The extent of the reduction of MTT to formazan was determined by measuring the absorbance at $540 \mathrm{~nm}$ using a microplate reader (ThermoMax, CA, USA)

\section{NO production}

Nitric oxide (NO) production in RAW264.7 cell culture supernatant was determined as described previously ${ }^{8}$ using the Griess reaction ${ }^{11}$.
Briefly, RAW 264.7 cells $\left(1.5 \times 10^{5}\right.$ cells/well) were plated in 24-well plates and incubated with different concentrations of RFE $(0.125,0.25,0.5$, and 1.0 $\mathrm{mg} / \mathrm{mL}$ ) and $1 \mathrm{ig} / \mathrm{mL}$ of LPS for $24 \mathrm{~h}$. One-hundred microliters of cell culture medium was mixed with $100 \mu \mathrm{L}$ of Griess reagent [ $1 \%$ sulfanilamide and $0.1 \%$ naphthylethylenediamine dihydrochloride in $2.5 \%$ phosphoric acid]. The mixture was incubated at room temperature for $10 \mathrm{~min}$ and the absorbance was measured at $540 \mathrm{~nm}$ using a microplate reader. In all experiments, fresh culture medium was used as the blank and the concentration of nitrite was calculated according to the standard curve generated from known concentrations of sodium nitrite $\left(\mathrm{NaNO}_{2}\right)$.

\section{PGE $_{2}$, IL-6, and IL-1 $\beta$ production}

RAW 264.7 cells $\left(1.5 \times 10^{5}\right.$ cells/well) were plated in 24-well plates and incubated in an atmosphere of $5 \% \mathrm{CO}_{2}$ at $37^{\circ} \mathrm{C}$ for $18 \mathrm{~h}$. After elimination of the culture medium, RAW 264.7 cells were incubated with different concentrations of $\operatorname{RFE}(0.125,0.25,0.5$, and $1.0 \mathrm{mg} / \mathrm{mL})$ and $1 \mu \mathrm{g} / \mathrm{mL}$ of LPS for $24 \mathrm{~h}$. The production of $P G E_{2}$ and cytokines was quantified by using mouse enzymelinked immunosorbent assay (ELISA) kits (R\&D Systems, Minneapolis, MN, USA) according to the manufacturer's instructions. All experiments were performed in triplicate.

\section{Western blot analysis}

RAW 264.7 cells $\left(1.0 \times 10^{6}\right.$ cells $\left./ \mathrm{mL}\right)$ were preincubated in a $60-\mathrm{mm}$ petri dish in an atmosphere

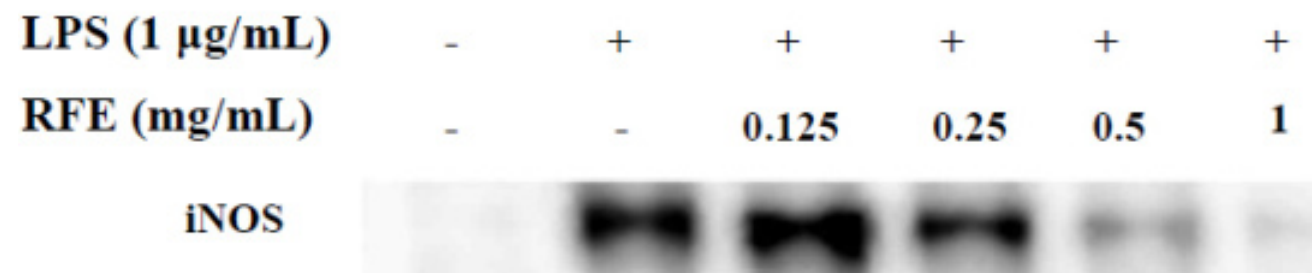

COX2

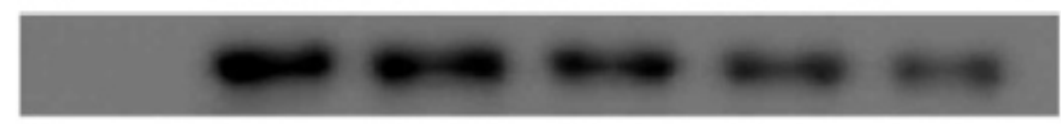

$\beta$-actin

Fig. 3: Effects of RFE on iNOS and COX-2 expression in LPS-stimulated RAW264.7 murine macrophages. Cells $\left(1.0 \times 10^{6}\right.$ cells $\left./ \mathrm{mL}\right)$ were pre-incubated for $18 \mathrm{~h}$ and then treated with LPS $(1 \mu \mathrm{g} / \mathrm{mL})$ and RFE for $24 \mathrm{~h}$. iNOS and COX-2 protein levels were analyzed by western blot 
of $5 \% \mathrm{CO}_{2}$ at $37^{\circ} \mathrm{C}$ for $18 \mathrm{~h}$. After elimination of the culture medium, RAW 264.7 cells were incubated with different concentrations of RFE $(0.125,0.25$, 0.5 , and $1.0 \mathrm{mg} / \mathrm{mL}$ ) and $1 \mu \mathrm{g} / \mathrm{mL}$ of LPS for 24 h. After incubation, the cells were collected and washed twice with cold phosphate buffered saline (PBS). The cell lysates were centrifuged and protein concentration was determined using a Bio-Rad protein assay kit (Bio-Rad, Hercules, CA, USA) with bovine serum albumin (BSA) as a standard. Aliquots of the lysates (30-40 $\mathrm{mg}$ of protein) were separated on a $10 \%$ SDS-polyacrylamide gel and transferred onto a polyvinylidene fluoride (PVDF) membrane for $2 \mathrm{~h}$. The membranes were preincubated with blocking solution (5\% skim milk in Tris-buffered saline containing Tween-20) at $4{ }^{\circ} \mathrm{C}$ overnight and then incubated with an anti-mouse iNOS and anti-mouse COX-2 (1:1000; Santa Cruz Biotechnology, Santa Cruz, CA, USA) for $2 \mathrm{~h}$ at room temperature. After washing, the blots were incubated with horseradish peroxidase conjugated goat anti-mouse IgG secondary antibody (1:5000;

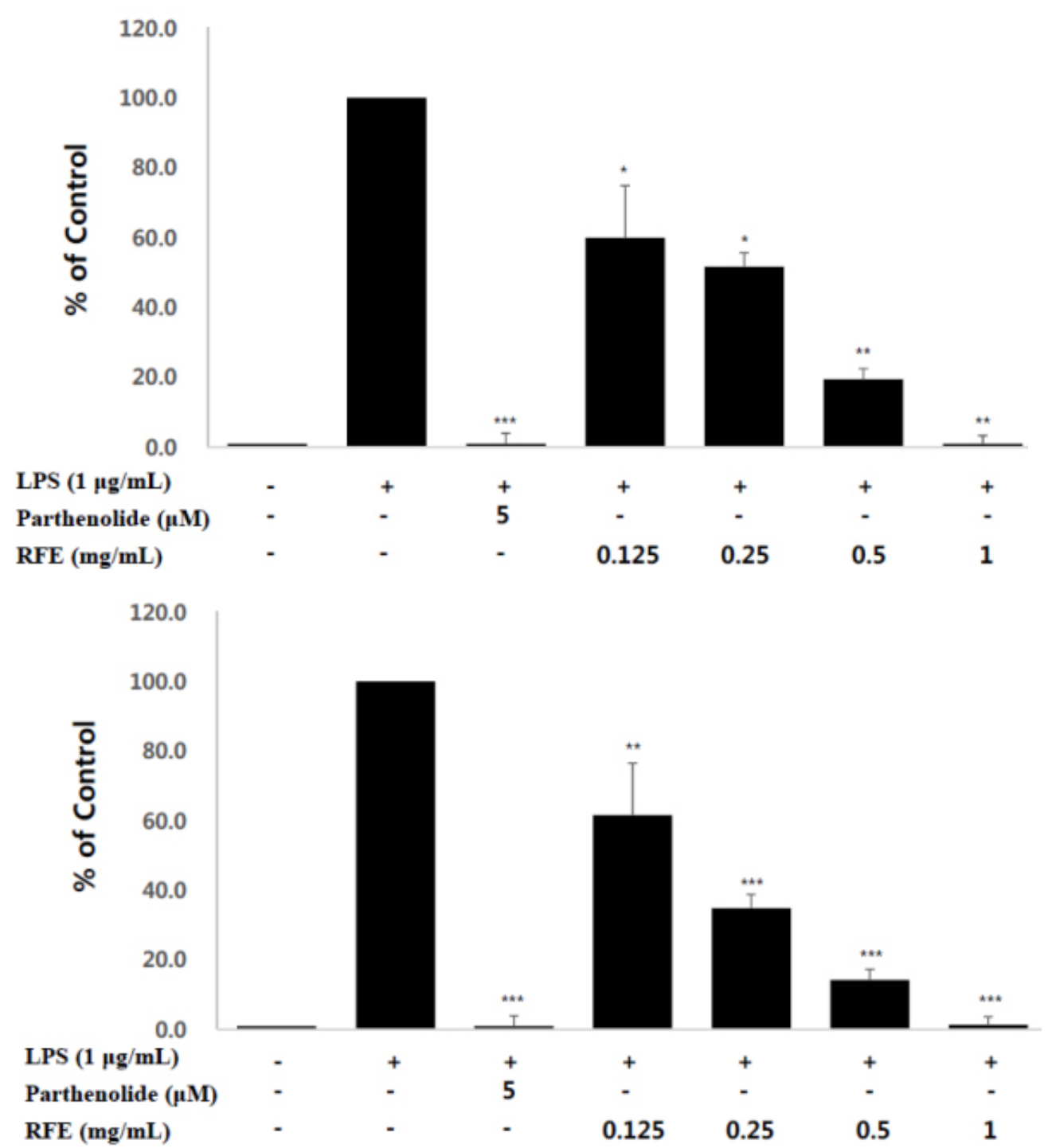

Fig. 4: Effects of RFE on IL-6 (A) and IL-1 $\beta$ (B) production in LPS-stimulated RAW264.7 murine macrophages. Cells ( $1.5 \times 10^{5}$ cells $\left./ \mathrm{mL}\right)$ were pre-incubated for $18 \mathrm{~h}$ and IL- 6 and IL-1 $\beta$ production was determined in the cells stimulated with LPS $(1 \mu \mathrm{g} / \mathrm{mL})$ in the presence or absence of RFE for 24 h. $\mathbf{n}=3$ experiments. *, $\mathrm{P}<0.05$; **, $\mathrm{P}<0.01$ 
Vector Laboratories, Burlingame, CA, USA) for 40 min. The immunoreactive proteins were detected by ECL Western blotting detection kit (Amersham Biosciences, Piscataway, NJ, USA).

\section{High-performance liquid chromatograph (HPLC) fingerprinting}

Since coumestrol was reported as a component of rape sp. and is known to present anti-inflammatory properties, we investigated the presence of this compound in the $70 \%$ ethanolic extract of rape flower ${ }^{12}$. The chromatographic analysis of RFE was performed using HPLC with a Waters e2695 separation module (Waters, Milford, MA, USA) coupled to a Waters 2489 UV visible detector, utilizing a YMC Pro $\mathrm{C}_{18}$ RS column (250 x $4.6 \mathrm{~mm}$; YMC Co., Kyoto, Japan) at a flow rate of 0.6 $\mathrm{mL} / \mathrm{min}$, The column was placed in a column oven at $40^{\circ} \mathrm{C}$.

\section{Human skin primary irritation test}

RFE human skin irritation test was performed by Dermapro Inc. (Seoul, Korea) based on the Declaration of Helsinki. Thirty-two healthy female Korean subjects were selected based on inclusion and exclusion criteria and written consent was obtained in each case. The average age was $41.8 \pm 7.2$ years (range: $20-50$ years). The subjects had no history of allergic contact dermatitis. They did not use topical or systemic irritant preparations in the month prior to the study. The human skin primary irritation test was performed using a Finn Chamber $\circledast$ secured to the back with micropore tape. RFE formulated with butylene glycol was prepared and $16 \mu \mathrm{L}$ of RFE at a concentration of $1 \mathrm{mg} / \mathrm{mL}$ and $2 \mathrm{mg} / \mathrm{mL}$ were applied. The patches (chambers) remained in place for $48 \mathrm{~h}$. The subjects abstained from showering or performing any work or exercise that might wet or loosen the patches. Once the patches were removed, the site was observed $48 \mathrm{~h}$ and $72 \mathrm{~h}$ later. The readings were scored according to the criteria of Frosch and Kligman ${ }^{13}$ and Personal Care Product Council (PCPC) guidelines.

\section{Statistical analysis}

All data are presented as means \pm S.D. and into relative percentage. Statistical comparisons between groups were performed using Student's $t$ test. $P<0.05$ was considered statistically significant.

\section{RESULTS AND DISCUSSION}

The regulation of NO production and iNOS protein expression are considered useful targets for the screening of anti-inflammatory materials because $\mathrm{NO}$ is closely associated with chronic inflammation. NO production is the hallmark of RAW 264.7 macrophage cell activation and reaches a maximal level after $24 \mathrm{~h}$ of incubation with LPS ${ }^{14}$. Therefore, we used this time point to assess the effect of RFE on NO production. Macrophage cells were stimulated with LPS and nitrite (NO stable metabolite) levels in the conditioned medium were monitored by using the Griess reaction, a spectrophotometric determination for nitrite. As shown in Figure 1, stimulation with LPS markedly increased nitrite levels compared to control after $24 \mathrm{~h}$ of incubation. In this assay system,

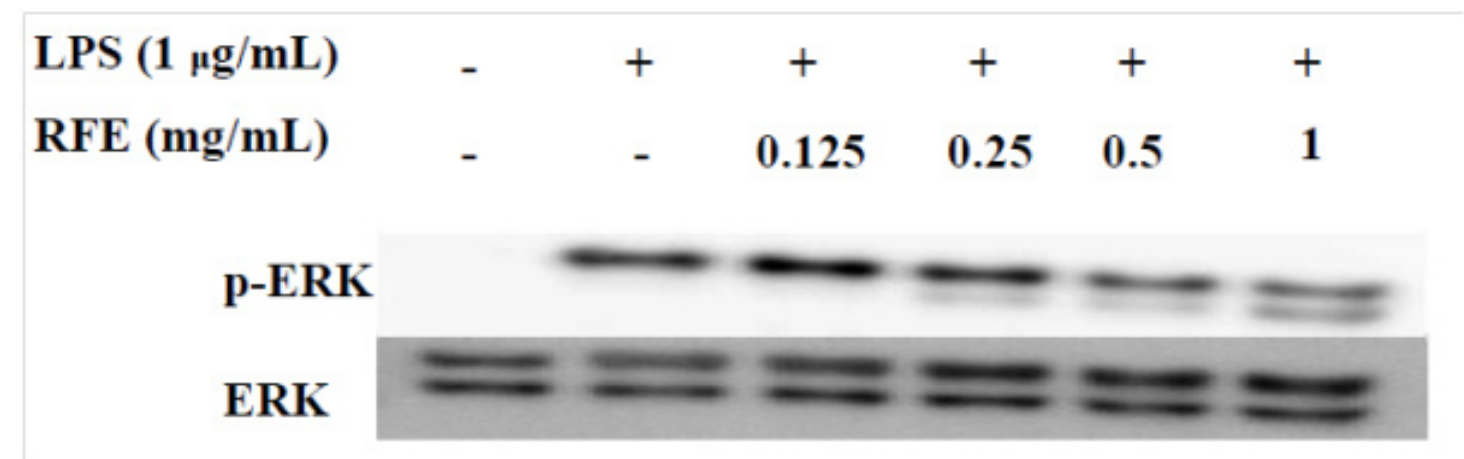

Fig. 5: RFE inhibitory effects on ERK expression in LPS-stimulated RAW264.7 murine macrophage. Cells $\left(1.5 \times 10^{6}\right.$ cells $\left./ \mathrm{mL}\right)$ were pre-incubated for $18 \mathrm{~h}$ and then treated with LPS $(1 \mu \mathrm{g} / \mathrm{mL})$ and RFE for $15 \mathrm{~min}$. p-ERK and ERK protein levels were determined by western blotting 
parthenolide (5 ì), an inhibitor of nuclear factorkappaB (NF-êB) pathway used as a positive control, inhibited NO production by $97.3 \%$. RFE $(0.125$, $0.25,0.5$, and $1.0 \mathrm{mg} / \mathrm{mL}$ ) significantly inhibited $\mathrm{NO}$ production in a concentration-dependent manner, with an $\mathrm{IC}_{50}$ value of $0.39 \mathrm{mg} / \mathrm{mL}$. RFE at $0.5 \mathrm{mg} / \mathrm{mL}$ induced a $61.7 \%$ inhibition of NO production. MTT assay indicated that the number of viable activated macrophages was not altered by RFE, indicating that the inhibition of NO production by RFE was not simply due to cytotoxic effects.

A large body of evidence suggests that $P \mathrm{PE}_{2}$ is involved in various pathophysiological processes, including inflammation and carcinogenesis. It is produced from the conversion of arachidonic acid by the inducible cyclooxygenase isoform, COX-2, which is induced by cytokines and other activators

Auto-Scaled Chromatogram

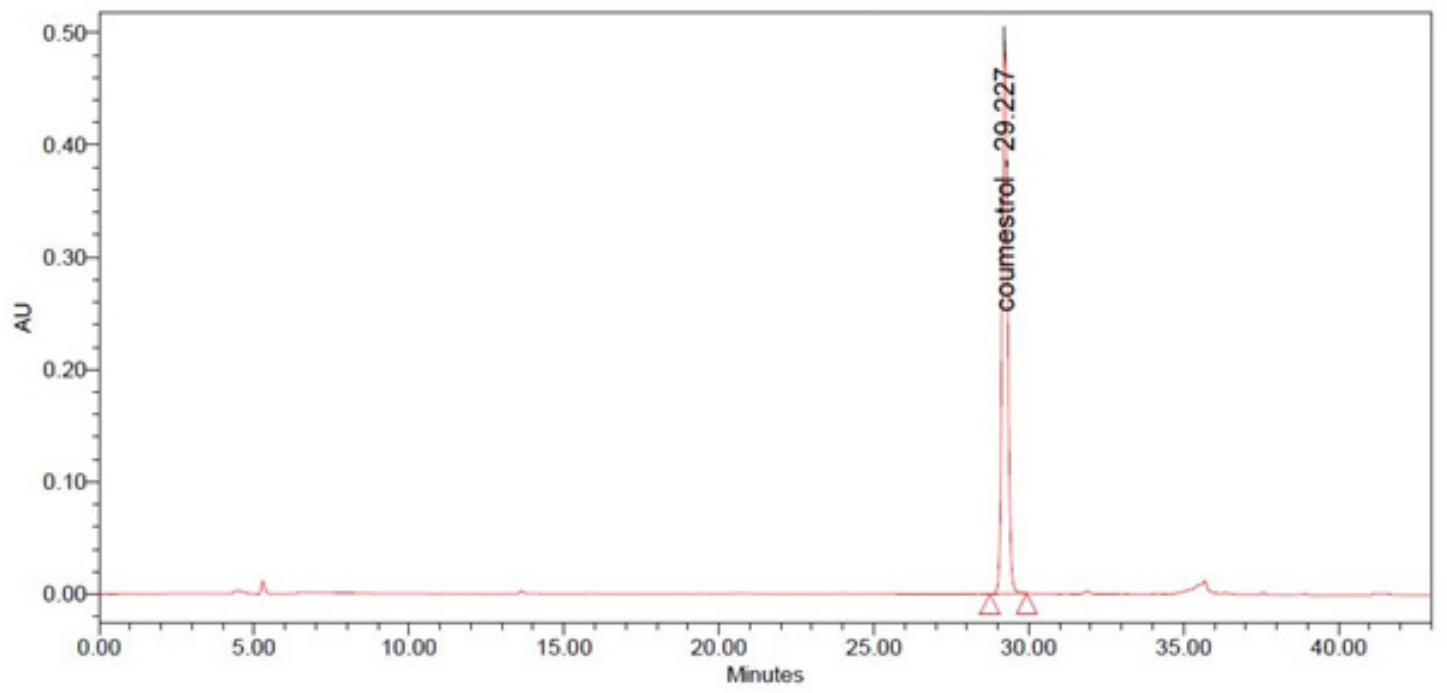

Auto-Scaled Chromatogram

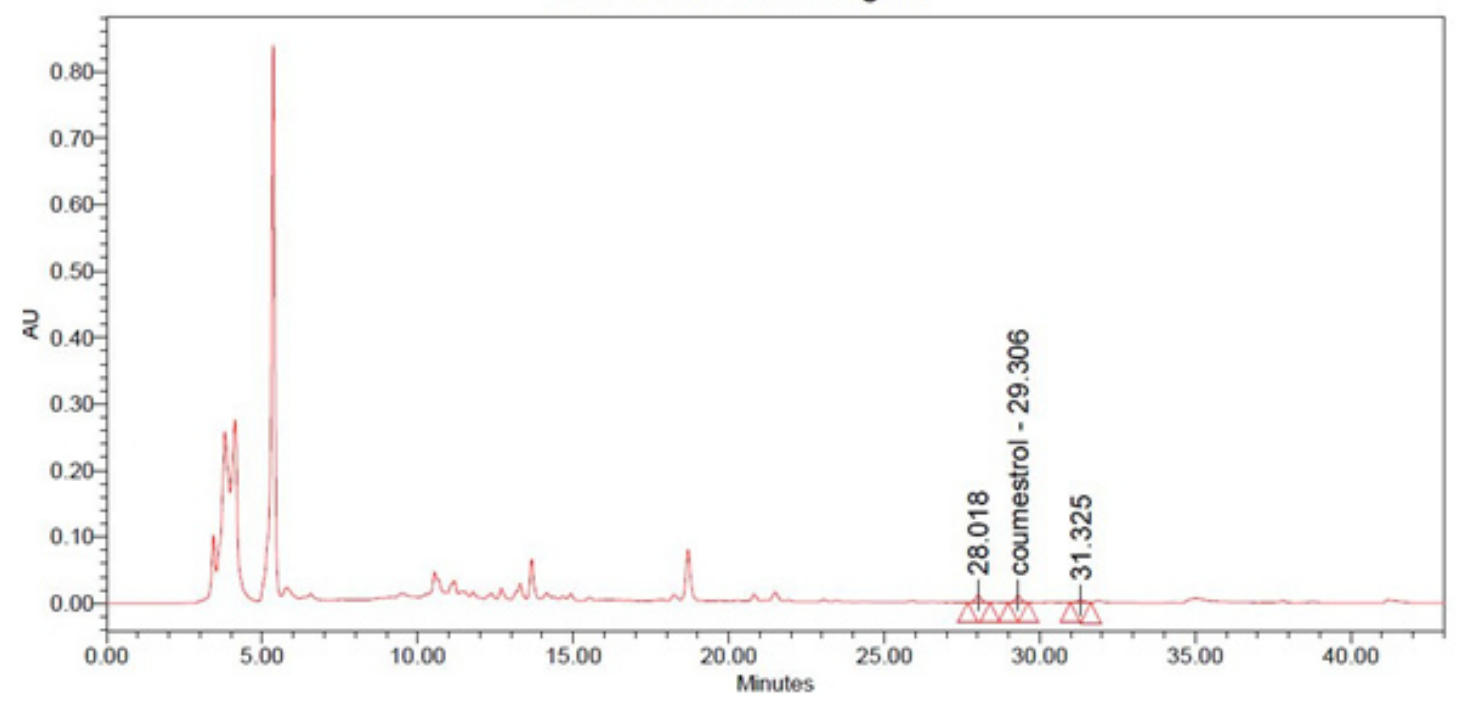

Fig. 6: HPLC fingerprinting analysis of RFE. The upper side represents standard coumestrol. Coumestrol is detected at a wavelength of $280 \mathrm{~nm}$ 
such as LPS ${ }^{15}$. Therefore, we next examined the effects of RFE on PGE $_{2}$ production in LPS-stimulated RAW 264.7 macrophages. To determine the inhibitory effect of RFE on $\mathrm{PGE}_{2}$ production, a $\mathrm{PGE}_{2}$ ELISA was used to assess the production of $\mathrm{PGE}_{2}$ in LPSstimulated RAW 264.7 cells. When RAW 264.7 cells were stimulated with LPS $(1 \mu \mathrm{g} / \mathrm{mL})$ for $24 \mathrm{~h}, \mathrm{PGE}_{2}$ levels dramatically increased in the culture medium. As shown in Figure 2, RFE significantly inhibited the $\mathrm{PGE}_{2}$ production induced by LPS, in a concentration dependent manner with an $\mathrm{IC}_{50}$ value of $0.63 \mathrm{mg} / \mathrm{mL}$. $\mathrm{NO}$ and $\mathrm{PGE}_{2}$ overproduction is mediated by the regulation of iNOS and COX-2 expression in LPSstimulated RAW 264.7 macrophages. To elucidate the mechanism involved in RFE-mediated inhibition of $\mathrm{NO}$ and $\mathrm{PGE}_{2}$ production, the effects of RFE on iNOS and COX-2 protein expression were determined by western blotting analysis. As shown in Figure 3, RFE suppressed LPS- stimulated overexpression of iNOS and COX-2 proteins in a concentration-dependent manner.

IL- $1 \beta$ and IL- 6 are mainly produced by activated monocytes or macrophages, and are the major proinflammatory cytokines. Moreover, RFE potently inhibited proinflammatory mediators. We further investigated its effects on LPS-induced IL-1 $\beta$ and IL- 6 release by ELISA. As shown in Figure 4, addition of LPS markedly increased IL-1 $\beta$ and IL-6 levels when compared to unstimulated macrophages. Treatment with increasing concentrations of RFE resulted in a dose-dependent reduction of IL$1 \beta$ and IL- 6 levels; IL- 1 levels were reduced by $38.3 \pm 3.1 \%, 65.1 \pm 1.9 \%, 85.8 \pm 0.9 \%$, and 98.7 $\pm 1.4 \%$, while IL-6 levels were reduced by 40.1 $\pm 9.4 \%, 48.3 \pm 9.4 \%, 80.6 \pm 6.2 \%$, and $99 \pm 0.2 \%$ when cells were treated with $0.125,0.25,0.5$, and $1.0 \mathrm{mg} / \mathrm{mL}$ RFE, respectively. LPS activates not only NF-êB, but also activates MAPK family members such as JNK, ERK, and p38. The MAPK signaling pathway also plays a crucial role in the induction of pro-inflammatory cytokines ${ }^{16}$. As shown in Figure 5, RFE suppressed the activation (phosphorylation) of ERK in LPS-stimulated RAW 264.7 cells. These data suggest that the anti-inflammatory activity of RFE is associated with the suppression of the MAPK signaling pathway.

HPLC fingerprint, a chromatographic method, was highly recommended for developing standard substances from raw materials ${ }^{17}$. We used HPLC fingerprint technology to determine the presence of coumestrol, a component of rape plants known to have anti-inflammatory properties. Using the conditions described in the Materials and Methods section, coumestrol was detected in RFE with an excellent peak shape. The coumestrol content in RFE was 2.614 iM (Fig. 6). Finally, to evaluate the irritation effects of RFE on the human skin, patch tests were performed. As shown in Table 1, no severe adverse reaction such as erythema, burning, or pruritus related to topical treatment with RFE was observed. Taken together, our results suggest that RFE may be considered as an anti-inflammatory candidate for topical application.

\section{ACKNOWLEDGEMENTS}

This research was supported by the Industrial Cluster Strengthening Competitiveness Program (Daebul 14-RND2) which is managed by the Korea Industrial Complex Corp.

\section{REFERENCES}

1. Lim, T.G.; Lee, C.C.; Dong, Z.; Lee, K.W.; Archives of Dermatological Research 2015, 307, 397-403.

2. Jeong, S.J.; Lim, H.S.; Seo, C.S.; Kim, J.H.; Jin, S.E.; Yoo, S.R.', Shin, H.K.; Phytomedicine, 2015, 22, 326-332.

3. Hossen, M.J.; Baek, K.S.; Kim, E.;Yang, W.S.; Jeong, D.; Kim, J.H.; Kweon, D.H.;Yoon, D.H.; Kim, T.W.; Kim, J.H.; Cho, J.Y.; Journal of
Ethnopharmacology, 2015, 159, 9-16.

4. Dua, A.; Chander, S.; Agrawal, S.; Mahajan, R.; Physiology and Molecular Biology of Plants, 2014, 20, 539-543.

5. Lozano-Baena, M.D.; Tasset, I.; ObregónCano, S.; de Haro-Bailon, A.; Muñoz-Serrano, A.; Alonso-Moraga, Á.; Molecules, 2015, 20, 15748-15765.

6. Choi, R.J.; Chun, J.; Khan, S.; Kim, Y.S.; 
International Immunopharmacology, 2014, 18, 182-190.

7. Lim, H.S.; Yeji, K.; Seo, C.S.; Yoo, S.R.; Jin, S.E.; Shin, H.K.; Jeong, S.J.; BMC Complementary and Alternative Medicine, 2015, 15:371.

8. Yang, E.J.; Ham, Y.M.; Lee, W.J.; Lee, N.H.; Hyun, C.G.; DARU Journal of Pharmaceutical Sciences, 2013, 21, 62.

9. Wu, K.; Mo, C.; Xiao, H.; Jiang, Y.; Ye, B.; Wang, S.; Planta Medica, 2015, 81, 821829.

10. Lou, T.; Jiang, W.; Xu, D.; Chen, T.; Fu, Y.; Inflammation, 2015, 38, 1213-1220.

11. Green, L.C.; Wagner, D.A.; Glogowski, J.; Skipper, P.L.; Wishnok, J.S.; Tannenbaum, S.R.; Analytical Biochemistry, 1982, 126, 131-138.
12. Liu, M.H.; Tsuang, F.Y.; Sheu, S.Y.; Sun, J.S.; Shih, C.M.; Neurological Research, 2011, 33, 663-672.

13. Frosch, P.J.; Kligman, A.M.; Journal of the American Academy of Dermatology, 1979, 1, 35-41.

14. Kang, H.J.; Hong, S.H.; Kang, K.H.; Park, C.; Choi, Y.H.; BMC Complementary and Alternative Medicine, 2015, 15, 447.

15. Kim, K.J.; Yoon, K.Y.; Yoon, H.S.; Oh, S.R.; Lee, B.Y.; International Journal of Molecular Sciences, 2015, 16, 27589-27598.

16. Kim, Y.S.; Ahn, C.B.; Je, J.Y.; Food Chemistry, 2016, 202, 9-14.

17. Yoon, W.J.; Ham, Y.M.; Yoo, B.S.; Moon, J.Y.; Koh, J.; Hyun, C.G.; Journal of Bioscience and Bioengineering, 2009, 107, 429-438. 